\title{
Managing Water Network using Geodatabase Concept
}

\author{
Samir Mahmud Adam ${ }^{2}$ \\ 2 Computer Science Department, Faculty Applied \\ Medicine, \\ Taif University, Kingdom of Saudi Arabia (KSA)
}

\author{
Magdy Shayboub Ali ${ }^{1,2^{*}}$ \\ 1 Computer Science Department, Faculty of \\ Computers and Informatics. Suez Canal \\ University, Egypt. \\ 2 Computer Science Department, Faculty Applied \\ Medicine, \\ Taif University, Kingdom of Saudi Arabia (KSA)
}

\begin{abstract}
In this paper, The purpose and the goal of the paper are to introduce a framework based on onto Geographical information systems (GIS) to integrate geographic information of Urban areas taking Khartoum State as an example. One of the main characteristics of such a framework is to support the information integration and data exchange between facilities using the base maps to solve the problem of distributing water networks. Entities in the Khartoum State (KS) infrastructure link information sources and lead to integration and exchange of associated information. The Methodology used is to study the existing urban systems specially water network using Geodatabase concept which are analyzed by observing and comparing the related earlier work using different criteria.
\end{abstract}

The Geodatabase of the system was defined, designed and build ArcGIS software. An object oriented geodatabase was created using GIS Software, then the information was gathered from Water, Sewage, Transportation Corporations in Khartoum States. The tools and software used are the Style Studio 2009 XML. Enterprise Suite Editor for driving KS Infrastructure geodatabase and KS Digital Base map was obtained from Khartoum State Surveying Corporation for Khartoum city center. Visual Basic for Application (VBA) was used to develop the Search Engine program. The main result obtained by the research is the development of a framework based on Geodatabase concept for the integration of geographic information of Khartoum State infrastructure network facilities.

The geodatabase of Khartoum State base map and facilities networks were completed by creating Multitask object oriented geodatabase using ArCatalog. A search engine code was written and tested ninety presents successful. The integration of information was available to exchange information between different Corporations to solve any problem that may damage the network facilities and to help managing and adding any new services on the site. The paper recommends the Building of multi-user unified geodatabase connected to a wide area network to service the concerned enterprise.

Keywords: GIS; Geodatabse, Water Network ,ArcGIS , KS , GML

\section{Introduction}

Information integration originating from different places The development and usage of Geographic Information System GIS is based among other things like knowledge representation. While geodatabase $[1,2]$ play an important role in information processing, as specifications of conceptualizations, enables sharing terms across different applications and thereby provide a way for application cooperation. Geodatabases are basis for data sharing, data processing, and data integration.

Geographical information systems (GIS), Open GIS Consortiums (OGC) [3], are sophisticated systems consisting of specialized software and hardware, generally used to analyze and visualize spatial-temporal information. The Integration of geographic data has gained an importance because of the new possibilities arising from the interconnected world and the increasing availability of geographic information. A large amount of geographical information is currently being stored on Khartoum State Land Base related to different site service companies and enterprises supplying working likes water, electricity, telecommunication and wastewater. In addition. the need for semantic geographical information is becoming very essential

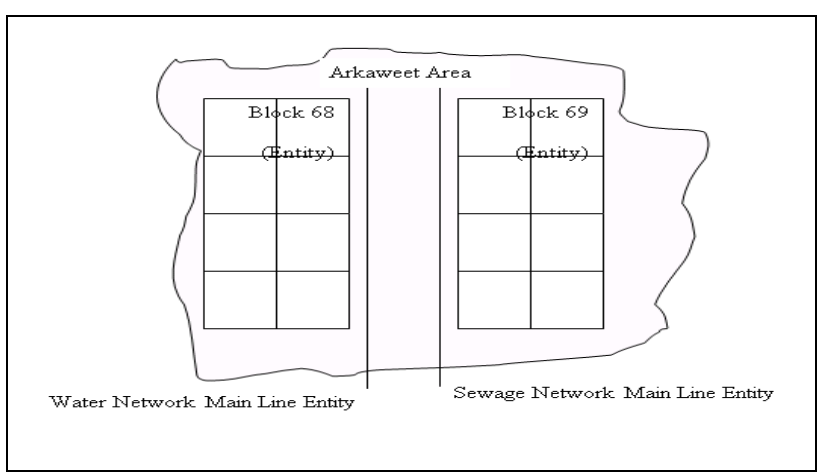

Fig. 1 shows the water network main line underground and the sewage main line

\subsection{Geo-KSWN Representing Geodatabases Hierarchies and Roles}

The services that offer the information to share (i.e., the information providers) or the services that want access to information (i.e., the information consumers) each have their own geodatabase. The level of detail of the geodatabases related to the level of detail of the geographic information of KS should integrate at different levels of detail. Therefore, two of the main questions of this thesis are "how can these geodatabases be combined, leading to information integration?" In addition, "what are the mechanisms for change of levels inside geodatabases?" The goal of this thesis is to find a mechanism for integrating GIS geodatabases and, consequently, for integrating geographical information system. This mechanism should provide a way to navigate at 
different levels in the geodatabase structure, because in order to answer user queries it is necessary to combine information at different levels of detail and consolidate information on a specific level.

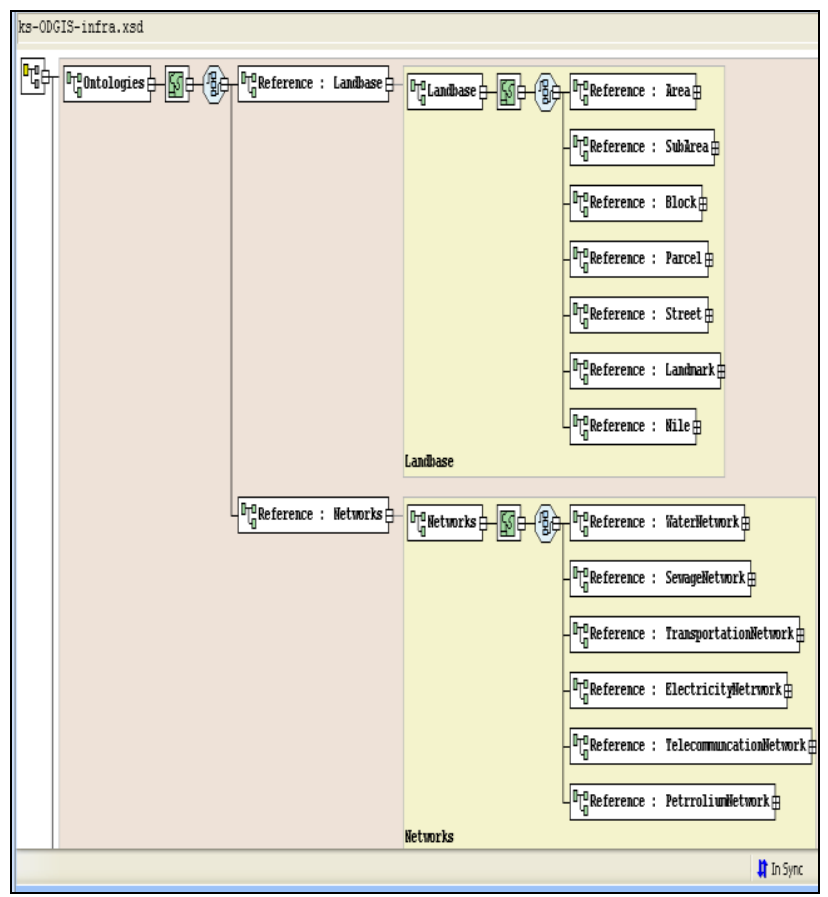

Fig. 2 shows the integrated land base and water network features datasets

\section{Infrastructure Services}

Consists of Domain geodatabase the geodatabse of the geographic area. Tasks and activities on the site like water, sewage and transportation services are considered. The software ArcCatelog version 9.2 was used to create and build the KS infrastructure personal Geodatabase of the KS land base and the feature datasets of Water Network , Transportation Network, sewage Network, electricity Network were designed on this work. Figure (3) shown the creation of new personal Geodatabase on Access Database

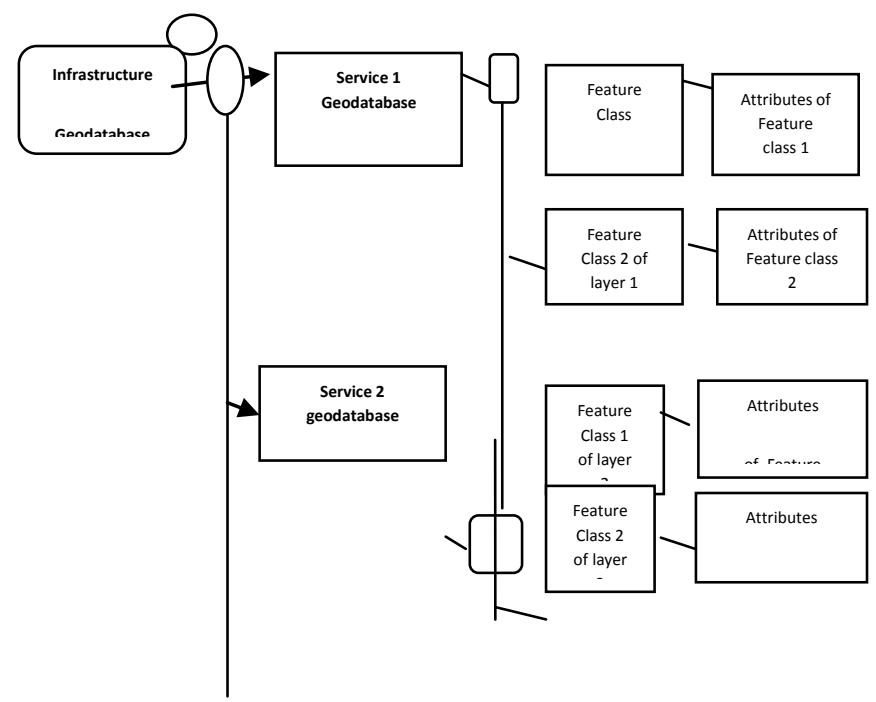

Fig. 3 The Navigation of the proposed Infrastructure Ontology layers.

\section{Land base layers}

They are Area, sub areas, blocks parcels and landmarks, Many services underground sharing the same land base on Khartoum stats three towns.

\subsection{Water supply services}

1-Water Rescores consists of :-

A-Water treatment plants

B-Wells there are two types of wells Mass production well and Normal Productions well see figure (5-3)

2- Water Network composed of

A-Main Line (Distribution or Transmission lines or service line)

B-Valves

C- Service line.

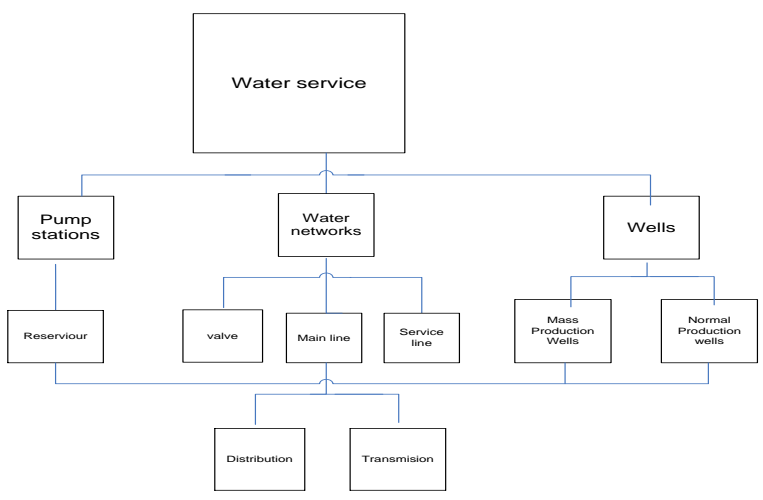

Fig. 4 Basic components of Water Network

The existing network of water map was found on an AutoCAD software some converted to ArcGIS the behavior the existence water network is close loop i.e. water coming from different resources to open area like treatment plants or boreholes while the other water system flow was the DMA (District Meter Area).

\subsection{Representation of Knowledge}

First, shown how the Khartoum state communities specify the geodatabases. Then it presented how the knowledge generated in the first phase of the system used. This section also presented the mechanism for changes of classes of KS infrastructure data integration and data sharing. This mechanism allows an instance of a class to be generalized or specialized thus enabling information integration at different levels. The different levels of information granularity and their relation to different levels of Geodatabse were discussed here. The navigation introduced here shortens the gap between generic and specialized Geodatabse, enabling the sharing of software components and information. The next section of this work presents an assessment of alternatives for integrating Geodatabse.

\subsection{Information integration}

Information integration was presented. The high-level integration of Geodatabases was discussed, followed by a discussion of low-level integration. A method for evaluating the potential for information integration was introduced. The measurement captures the effects of the use 
of roles and of hierarchical structures in the representation of Geodatabase in the potential for information integration.

\section{Guidelines for Implementation}

We are suggesting here specific tools for implementation. We know that these tools are not the only solutions but the evolution of ontology-driven information systems will lead to the use similar tools or to an evolution of these same tools. An ontology-driven information system deals with instances of classes [8-16].

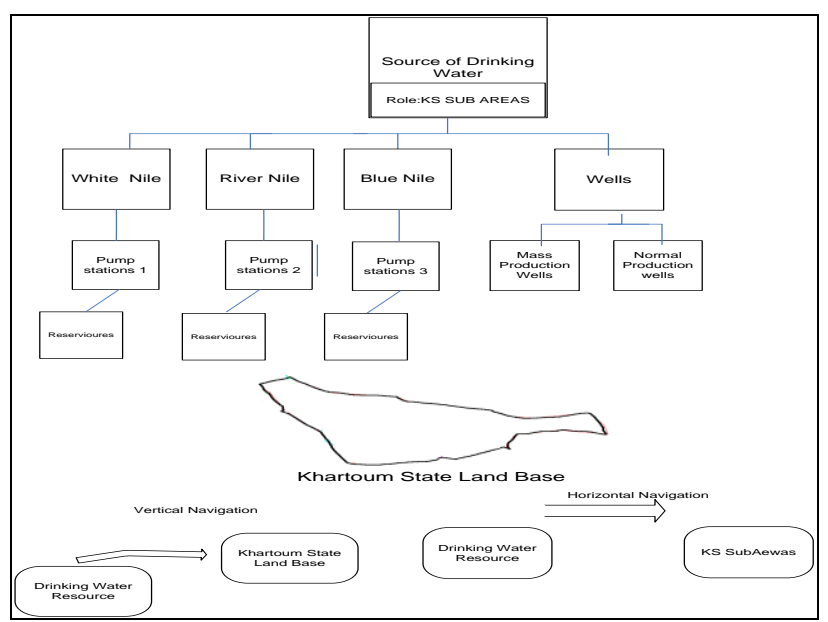

Fig. 5 Vertical and horizontal navigation of bodies of water.

\subsection{The steps of implementing the system}

- Editing the ontology tasks components

- Collection of data of the Infrastructures network components

- Collection of coordinate of the objects on the KS base map

- Collection of Customer information's

- Creation of KS Infrastructure Multi -Geodatabase using ArcGIS

- Developing the search dialog and customization using VBA [6]

\subsection{Infrastructure schema components}

Using XML syntaxes was used on style steel plat form software

The Example of language syntax of XML

\footnotetext{
$<$ ?xml version='1.0'?>

$<x$ sd:annotation>

$<x s d:$ documentation >

Khartoum State Infrastructure schema

$</ x s d:$ documentation $>$

$</ x$ sd:annotation $>$

$<$ xsd:element name="InfrastructureServices"

type="InfrastructureType"/>

<xsd: complexType name="InfrastructureType" >

$<x$ sd:sequence $>$

$<$ xsd:element ref="WaterNetworks"

type $="$ WaterType"/>

$<x$ sd:element ref="ElectricityNetworks"
}

type="EletricityType"/>

$<x$ sd:element ref="CommunicationNetwork"

type $="$ TelecommunicationType"/>

$<x$ sd:element ref="SewageNetwork"

type="SewgeType"/>

<xsd:element ref="TransportaionNetwork"

type $=$ "TransportationType

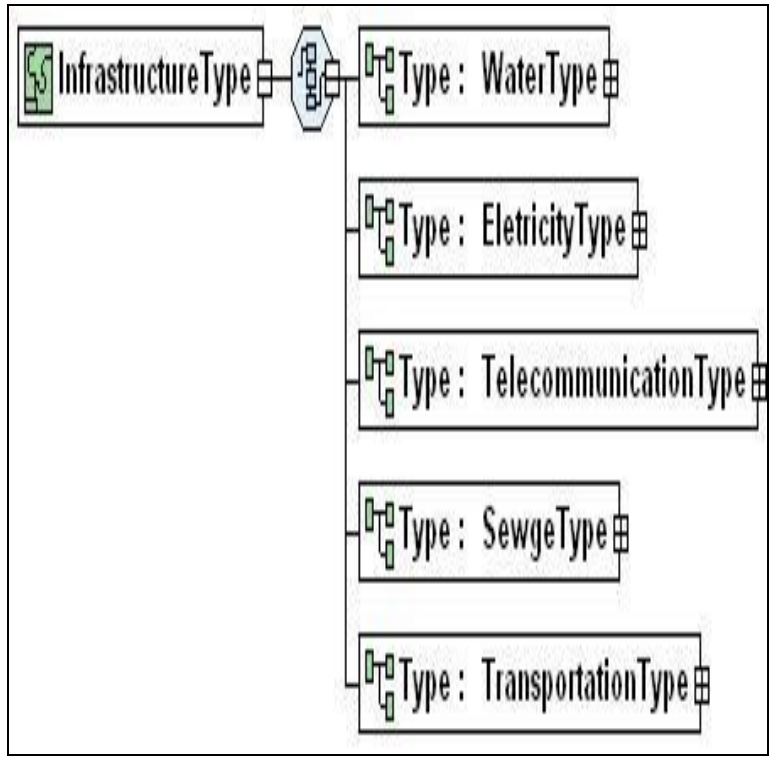

Fig. 6 KS Infrastructure using XML

\subsection{Water Network XML Schema}

<xsd: complexType name="WaterType">

$\langle\mathrm{xsd}$ :sequence>

$<x s d:$ element name $="$ Treatments plants" type $=$ "xsd: Geometry type=Point"/>

$<x$ sd: element name="wells" type $=$ "xsd: Geometry type $=$ Point"/>

$<x s d$ : element name $="$ Transmission lines" type="xsd: Geometry type $=$ Line"/>

$<x$ sd: element name="mainlines" type="xsd: Geometry type $=$ Line"/>

$<x s d$ : element name="Service line" type $=$ "Geometry type $=$ Line"/>

<xsd: element name="Valves" type $=$ "xsd: Geometry type $=$ point"/>

$</ x s d$ : sequence $>$

$</ x$ sd: complexType> 


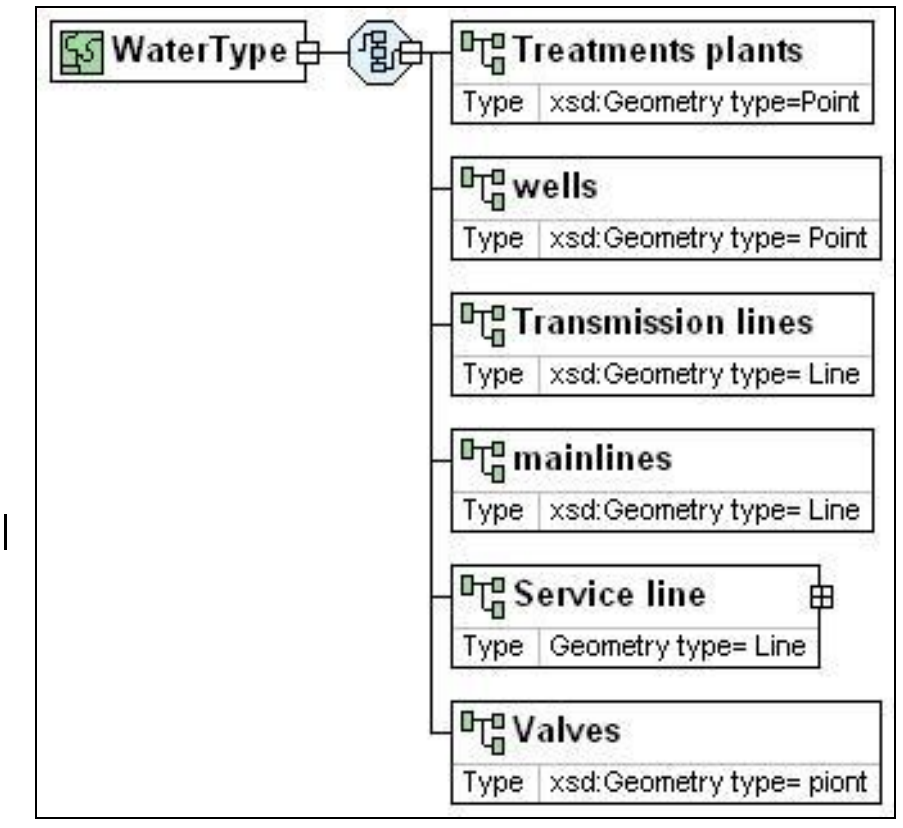

Fig. 7 Driving KS Water Network XML Diagram

\section{Data collection using GPS}

water network component was collected to implement the concept of ontology we started by collecting data for each KS.

| Infrastructure starting with water information_using field survey form see figure (7) show a simple database was designed using access visual basic to enter and print the data collection of each water network components, on the figure below there is a main form containing some of the water network components design on simple access form platform to print the form.

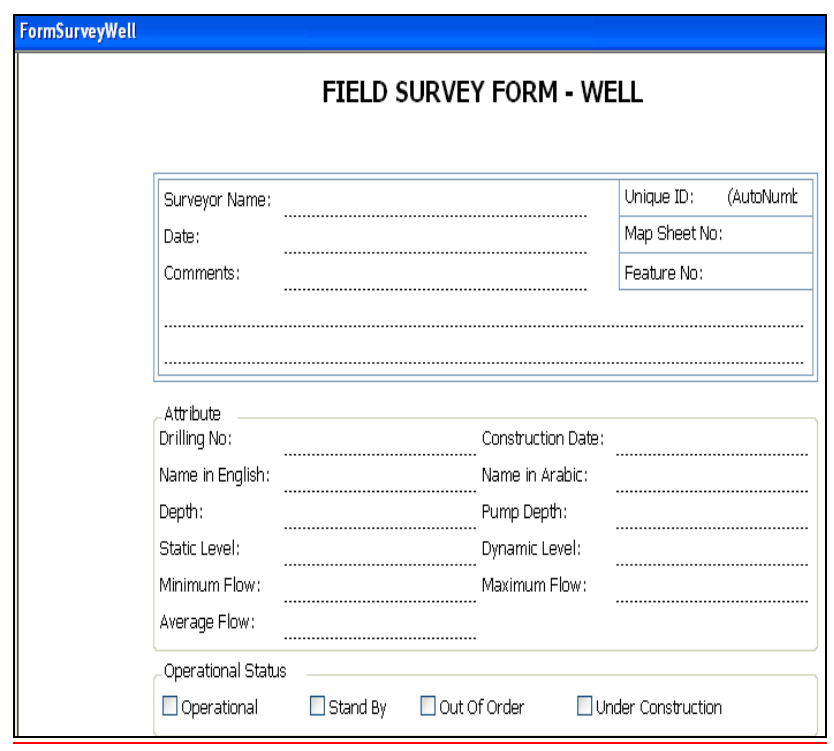

Fig. 8 Data collection form

The importance of GPS on data collection :

GPS was used is to raise the coordinate of the global positioning system which is a new technology having the following characteristics:

1-Constellation of 24 radio-navigation satellites in known orbits
2-Controlled and maintained by the US government

3-Several ground stations throughout the world

4-Free to use for civilians anywhere in the world

5-Provides accurate positions anywhere in the world using compatible receiver [18] GPS was use to record the position of the main line, valves and to know the place is the global positioning system which is a new technology having the following

\subsection{GIS and Customer information}

KSWC is involved in the management of a lot of information related to customers, networks, maintenance, operations, and design._Organizing and automating this amount of spatial data through GIS technology facilitates the planning, design, development and maintenance of water networks. Since the network changes so rapidly, the capability to find, manage, and analyze data quickly and effectively makes a strategic difference. Solving the business problems of a water network requires a good understanding of the network. Therefore, integrating in the day to day operation of KSWC is supposed to provide several advantages among them: GIS enables KSWC to integrate maps and information to make better decisions.

\subsection{GIS benefits' for water network}

GIS provides answers quickly to many issues regarding network:

1. Provisioning of Service

2. Planning and Maintaining Network Infrastructure

3. Managing Existing Customers

4. Finding New Customers

5. Administering network Coverage

GIS can be used in typical Automated Mapping Facilities Management tasks such as:

1. Planning

2. Engineering Design

3. Fault Tracing

\subsection{GIS and Water Customer Billing System}

GIS helps much on billing system, the relation between gis and billing system is take place by the field of gis-point, this field consists of the following fields:

The link between the map and the customer is by the creating a new number called GIS number. Joining the GIS and WATER Customer Billing System GIS helps much on billing system, the relation between GIS and billing system is take place by the field of parcel number on the parcel layer Geodatabase joined with the house number on the customer accounting master file database, and coloured the parcels on.

\section{Creations of Network Feature classes}

New feature classes can be created. , subtypes also can do creation of subtypes on ArcCatelog version 9.2 to make the editing easy and for reporting system. Infrastructure of KS was build and created which consists of GPS Survey Dataset for reading the coordinate systems, Sewage Network feature Dataset that consists of the five feature classes, Transportation Network Feature dataset consists of five features dataset, 
Water Network feature Dataset which consists of 16 feature classes.

\begin{tabular}{|c|c|c|c|}
\hline 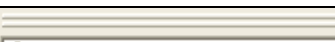 & $\underline{\underline{x}}$ & \begin{tabular}{|l|l|} 
Contents & Preview \\
\end{tabular} & Metadata \\
\hline Catalog & $\hat{\underline{n}}$ & Name & \\
\hline $\begin{array}{ll}+\infty \\
+\infty\end{array}$ & 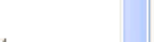 & GACTIONgames & \\
\hline+ E 期 Copy $C t x y+C$ & & Glazhari gis & \\
\hline$\square \mathrm{F}$ Paste $\quad \mathrm{ctrl}+\mathrm{V}$ & & 0 alriad gis2 & \\
\hline Rename $F 2$ & ffo7d4e1 & A Arkuit GIS & \\
\hline$+\infty$ Disconnect Folder & $514 f c e 521 b$ & GFuture Games & \\
\hline$+\approx$ Refresh & $\begin{array}{l}42 b 9 a \\
65 c e 08\end{array}$ & Gis- & \\
\hline+ New & $\square$ Folder & & \\
\hline Q search... & 0 File Geodat: & & 0 \\
\hline + E Pronerties & 0 Personal Ge & database & 09 Arcmap \\
\hline 1f017fele1db5f917b389d & $\diamond$ Layer... & & \\
\hline$+\square 2007$ & $\triangleq$ Group Layer & & \\
\hline $\begin{array}{l}+\square 2008 \\
+\square 2009\end{array}$ & $\square$ shapefile... & & \\
\hline$+20 f a 6108 c 78 \mathrm{ee} 7 \mathrm{dc} 41$ & क्ष & lationstip Class.... & \\
\hline$+921 f 5$ faa 01 b1 18403070 & Iurn Featur & Class..., & \\
\hline 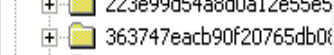 & (6) Toolbox & & \\
\hline$+\square$ 37cef83b58e52009aac22 & ArcInfo Wor & space & \\
\hline $\begin{array}{l}+\square \text { 48b5340f781eb5cb75 } \\
+\square 4 c 7 c 8703 f 500337 \mathrm{e} 7 \mathrm{c} 17 \mathrm{~d} 1\end{array}$ & 围 dBaSE Table & & \\
\hline
\end{tabular}

Fig. 9 Creation of personal Geodatabase

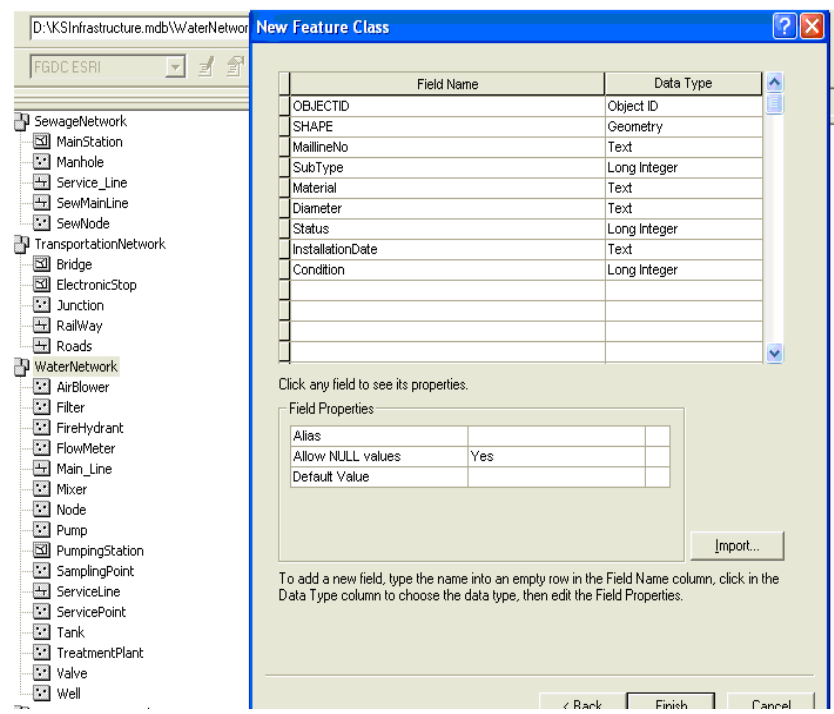

Fig. 10 The feature classes

\subsection{Creation of Infrastructure Geodatabase}

ArcCatelog version 9.2 was used to create and build the KS infrastructure personal Geodatabase of the KS land base and the feature datasets of Water Network, Transportation Network, sewage Network, electricity Network were designed [16-18].

Figure (8) shown the creation of new personal Geodatabase on Access Database

1. Design-time customization

2. Customize dialog box

3. Saving to the current map document

4. Saving to the Normal.mxd

\subsection{Example of Getting Coordinates Code}

Set $\mathrm{pMxDocument}=$ Application. Document

Set $\mathrm{pActiveView}=\mathrm{pMxDocument}$.FocusMap

Set pPoint $=$ pActiveView.ScreenDisplay.

DisplayTransformation.

ToMapPoint $(\mathrm{X}, \mathrm{Y})$

For finding layers Loop through layers of a map and Match the name were used by:

- Create a query filter

- Do the query

- $\quad$ Refresh the map

Zoom to Selected Feature was then used to :

- Retrieve the selected features

- Get selection's extent

- Reset map's extent

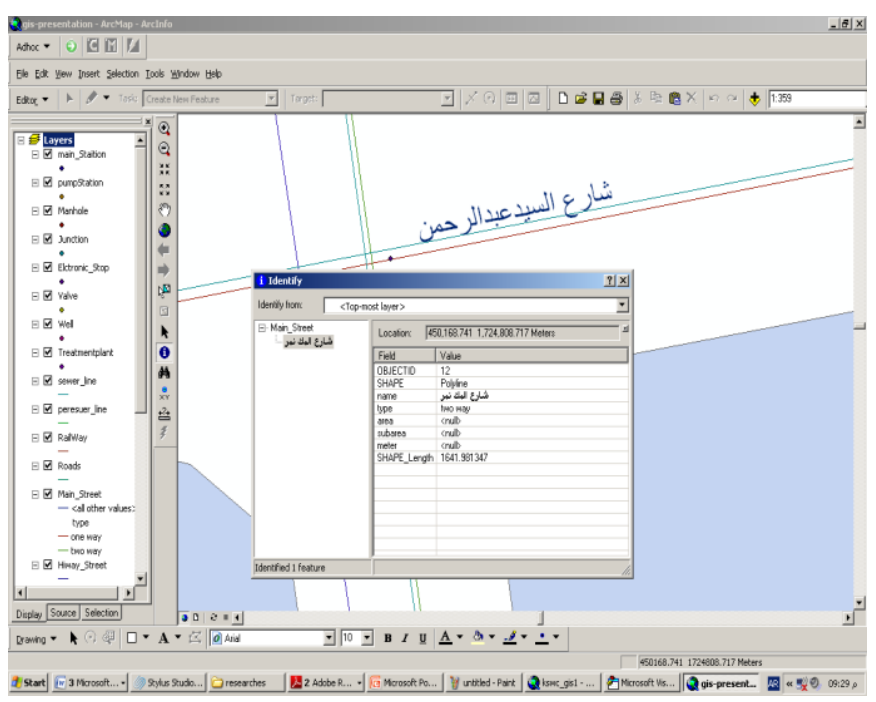

Fig. 11The sewer Main Line at AL Makk Nimer Street

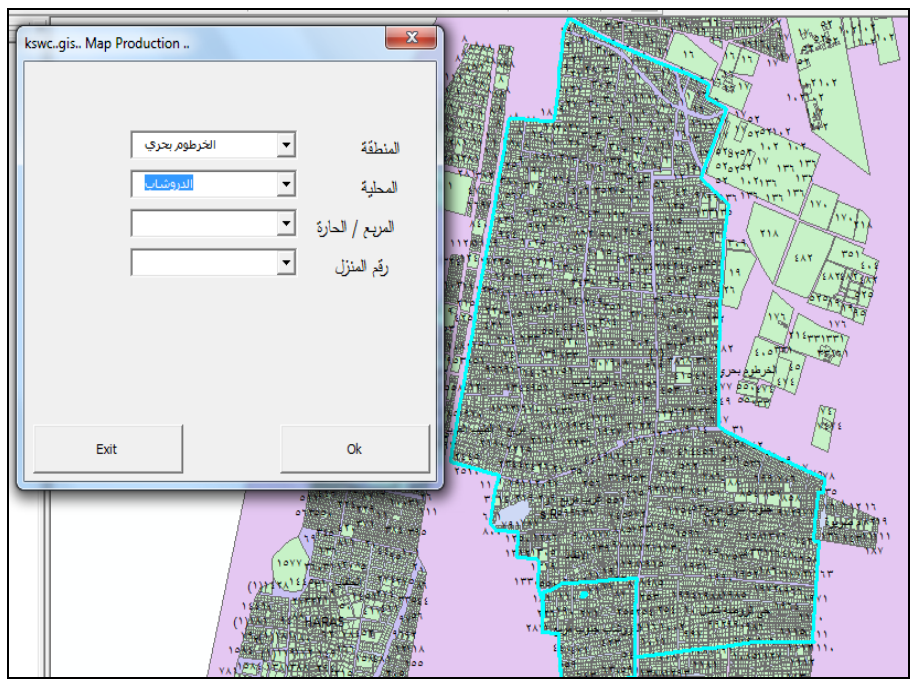

Fig.12 shows the search screen designed on ArcMap VBA Macro tool 
At Khartoum north base map search was done using VBA code to select area and sub area example in al Darwshab subarea, then select the block number or Haras then select then parcel number to view the water network exist in figure (10).

\subsection{Customization with ArcObject using VBA}

In these References $[3,8]$ shows the VBA code we used to develop the search on the ArcGIS KS map on the geodatabase of infrastructure "The input of the application was the landbase selection using combo box for dialog output is to locate an area, Subarea, block and parcel no, Searching on KS Landbase Using customization utility designed the searching on KS map aimed to:

\section{The View of the Geodatabase Feature}

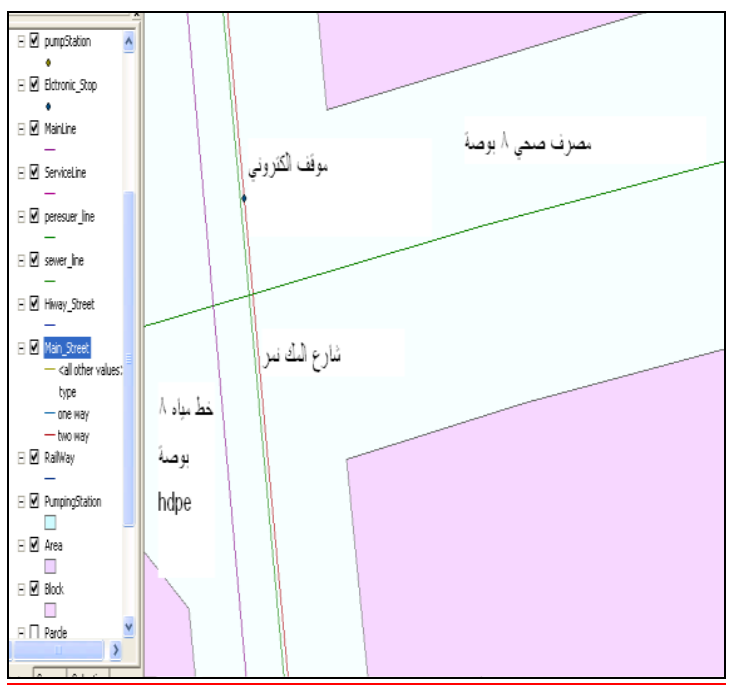

Fig. 13 The Ontology of the three infrastructures were exist on the same place

On the figure above, a sewer line made of Ductile 8 inches, a Main street of ALmakk Nimer, an Electronic stop and a Water pipe line of 8 inches type of HDPE were found this fact describe the aim of this thesis how can people of different enterprise can integrate their infrastructure knowledge on the same base map, which solve the problem of confusion between those different enterprise water, sewer, and transportation specially on maintenance activities.

\section{Conclusions and Future Work}

A novel ontology model was developed for the infrastructure GIS (in particular water network) using the Khartoum State Land base. GML language was used as an interface for building and editing ontologies . The benefits of using ontology is to share geodatabase of KS infrastructure among services existing on the same land in this case all corporations_and companies working on the KS land can share the data each having their own layer describing their services. Although ontologies are very powerful tools in data processing, there is still a lack of available and suitable ontologies .

\section{References}

[1] Czech, Zde.nka, Radim and Martin, "Building Ontologies for GIS". Institute of Computer ScienceAcademy of Sciences of the Czech Republic ,Zde.nka Linkovđ[a, Radim Nedbal, Martin ·Rimnđa $\cdot c$,Technical report No. 932, March 2005.
[2] Your Internet Guide to Geographic Information Systems http://www.gis.com. Geographic Information Systems (GIS). http://erg.usgs.gov/isb/pubs/gis_poster/

[3] Rahul Vemulapally, "Development of Standard Geodatabase Model and its Applications", February 03, 2010. http://portal.opengis.org/files/?artifact_id=3836.

[4] Stylus studio, Open Geospatial Consortium, Inc, Whiteside. All Rights Reserved, 2009.

[5] Aarcgisteamwater on March 6, 2009, http:ArcgisTeamWater@esri.com,Building and Maintaining Water Utility Geodatabases

[6] Khatib and Alami "VBA Code for Searching". A Consolidated Engineering Company , a member of ICON .2008.

[7] Pfleckl, Brandon, "Using ArcGIS Server to Manage Your Utility, Water, Wastewater, and Stormwater", 2010

http://sern.ucalgary.ca/KSI/KAW/KAW99/papers/Erdm ann1/erdmann.pdf.

[8] Erdmann, M. and Studer, R. "Ontology as conceptual models for XML documents". In Proceedings of the 12th Workshop on Knowledge Acquisition, Modeling and Management (KAW'99), 1999. Knowledge Science Institute, University of Calgary

[9] Alani, H., Kim, S., Millard, D. E., Weal, M. J., Hall, W., Lewis, P. H., and Shadbolt, N.R., 2003, "Automatic Ontology-Based Knowledge Extraction from Web Documents", IEEE Intelligent Systems, Vol. 10, No 1, pp.14-21.

[10] John F. Sowa, "Guided Tour of Ontology"; http://www.jfsowa.com/ontology/guided.htm

[11] F. Gandon, "Ontology Engineering: a survey and a return on experience", Research Report of INRIA, France, March 2002.

[12] Kay, M. "XSLT Programmer's Reference", Wrox Press Ltd., USA, chapter 4, 2000. http://www.w3.org/standards/xml

[13] Fensel, D., "Ontologies: A Silver Bullet for Knowledge Management and Electronic Commerce", 2004. Springer.

[14] Dumontier M, Villanueva-Rosales N. "Three-layer OWL ontology design". In: Second international workshop on modular ontologies (WOMO07), Whistler, Canada, 2007.

[15] Noy NF, McGuinness DL. "Ontology development 101: a guide to creating your first ontology"; 2001. Report No.: Stanford Knowledge Systems Laboratory Technical Report KSL-01-05, Stanford Medical Informatics Technical Report SMI-2001-0880.

[16] Smith B, Ceusters W, Klagges B, Kohler J, Kumar A, Lomax J, et al. Relations in biomedical ontologies. Genome Biol 2005;6(5):R46.

[17] T.P. Liang, H.J. Lai, Y.C. Ku, "Personalized content recommendation and user satisfaction: theoretical synthesis and empirical findings", Journal of Management Information Systems 23 (3), p.p 45-70, 2006. 
[18] Goodchild, M., Egenhofer, M., Fegeas, R., and Kottman, C, "Interoperating Geographic Information Systems". Kluwer Academic Publishers, Norwell, MA,1999.

\section{AUTHOR'S PROFILE}

Samir M. Adam was born in Elfashir , on November 21, 1959.Graduated from U of G Faculty of Science and Technology in 1986 with a B.Sc.degree in Electronics, Instrumentation and applied physics .Graduated from $\mathrm{U}$ of $\mathrm{K}$ faculty of Mathematical Science Department of Computer with a M.Sc Degree in Computer Science 1996 .Ph.D in Computer Science University of Khartoum 2012. Computer programmer in NEC from 1986 until 1994Chief of Computer programmer section NEC from 1990-1994 .Omharaz NEC Computer Training Center manager 1994-1996.Computer teacher, Ministry of Education at Saudi Arabia from 1996 till 1999. Now is working an assistant professor of computer science at the Faculty of applied Medicine in Taif University, Kingdom of Saudi Arabia.

Magdy Shayboub Was born in El- Menoufia, Egypt, in 1966. $\mathrm{He}$ received the B.Sc. degree in Electronic Engineering in 1989, and M.Sc. degree for his work in Computer Science and Engineering in 1998, all from the Faculty of Electronic Engineering, Menoufia University, Egypt. In 2005, he received his $\mathrm{Ph}$. D. in Computer Science from Faculty of Computers and Informatics from Helwan University, Egypt. $\mathrm{He}$ is working as an assistant professor of computer science at the Faculty of Computers and Informatics, Suez Canal University, Egypt from 2006 until now. His research interests are in Artificial Intelligent (AI) Applications and Intelligent Agents (IA), Information Retrieval, Computer Networks Security and Semantic Web. Now is working a head of Medical Records Department and computer science in the Faculty of applied Medicine Science in Taif University, Kingdom of Saudi Arabia. 